\title{
Prognostic and Therapeutic Roles of the Insulin Growth Factor System in Glioblastoma
}

\author{
Elena Tirrò ${ }^{1,2^{*}+}$, Michele Massimino ${ }^{1,2 \dagger}$, Chiara Romano ${ }^{1,2}$, Federica Martorana ${ }^{1,2,3}$, \\ Maria Stella Pennisi ${ }^{1,2}$, Stefania Stella ${ }^{1,2}$, Giuliana Pavone ${ }^{2,3}$, Sandra Di Gregorio ${ }^{1,2}$, \\ Adriana Puma ${ }^{1,2}$, Cristina Tomarchio ${ }^{1,2}$, Silvia Rita Vitale ${ }^{1,2}$, Livia Manzella ${ }^{1,2}$ \\ and Paolo Vigneri ${ }^{1,2,3}$
}

${ }^{1}$ Department of Clinical and Experimental Medicine, University of Catania, Catania, Italy, ${ }^{2}$ Center of Experimental Oncology and Hematology, A.O.U. Policlinico "G. Rodolico-San Marco", Catania, Italy, ${ }^{3}$ Medical Oncology, A.O.U. Policlinico "G. Rodolico-San Marco", Catania, Italy

OPEN ACCESS

Edited by:

Maria Caffo,

University of Messina, Italy

Reviewed by:

Filippo Flavio Angileri,

University of Messina, Italy

Giovanni Raffa,

University of Messina, Italy

*Correspondence:

Elena Tirrò

ele_tir@yahoo.it

${ }^{+}$These authors have contributed equally to this work

Specialty section:

This article was submitted to Neuro-Oncology and

Neurosurgical Oncology,

a section of the journal

Frontiers in Oncology

Received: 30 September 2020 Accepted: 16 December 2020 Published: 02 February 2021

Citation:

Tirrò E, Massimino M, Romano C, Martorana F, Pennisi MS, Stella S, Pavone G, Di Gregorio S, Puma A, Tomarchio C, Vitale SR, Manzella L and Vigneri P (2021) Prognostic and

Therapeutic Roles of the Insulin

Growth Factor System in

Glioblastoma.

Front. Oncol. 10:612385.

doi: 10.3389/fonc.2020.612385
Glioblastoma multiforme (GBM) is the most common primary brain malignancy and is often resistant to conventional treatments due to its extensive cellular heterogeneity. Thus, the overall survival of GBM patients remains extremely poor. Insulin-like growth factor (IGF) signaling entails a complex system that is a key regulator of cell transformation, growth and cell-cycle progression. Hence, its deregulation is frequently involved in the development of several cancers, including brain malignancies. In GBM, differential expression of several IGF system components and alterations of this signaling axis are linked to significantly worse prognosis and reduced responsiveness to temozolomide, the most commonly used pharmacological agent for the treatment of the disease. In the present review we summarize the biological role of the IGF system in the pathogenesis of GBM and comprehensively discuss its clinical significance and contribution to the development of resistance to standard chemotherapy and experimental treatments.

\footnotetext{
Keywords: insulin/insulin-like growth factor system, insulin-like growth factor signaling pathway, IGF-binding protein, glioblastoma, drug resistance
}

\section{INTRODUCTION}

Malignant gliomas represent $30 \%$ of all intracranial tumors and include a heterogeneous group of neoplasms that arise from multiple cell types with neural stem cell-like properties (1). In the US, the annual incidence of gliomas is 3.2 cases for every 100,000 individuals and about half of them are classified as glioblastoma or glioblastoma multiforme (GBM) (2). Incidence increases with age and is more common in men than in women and in individuals of caucasian ethnicity (3). Disease prognosis is poor, with a $35 \%$ survival rate at 1 year and $<5 \%$ at 5 years (4). GBM can be classified as primary when it develops within a few months without known precursor states, or secondary, when a low-grade tumor evolves in a GBM. Surgery, radiation therapy and chemotherapy with alkylating agents such as temozolomide (TMZ) represent the mainstay of GBM treatment (5). Additionally, several small molecules have been tested in the last few years $(6,7)$. However, none of these strategies represent an effective cure for GBM, as this malignancy displays extensive intra-tumoral heterogeneity that favors disease recurrence $(8,9)$. Genomic profiling carried out by the The Cancer 
Genome Atlas (TCGA) consortium on 200 GBM samples as well as a complementary study by Pearson and colleagues revealed recurrent genetic alterations involving TP53, retinoblastoma $(R b)$ and different receptor tyrosine kinases (RTK) pathways $(10,11)$.

RTKs are a family of cell surface receptors, comprising the epidermal growth factor receptor (EGFR), the fibroblast growth factor receptor (FGFR), the hepatocyte growth factor receptor (HGFR/c-MET), the platelet-derived growth factor receptor (PDGFR), the vascular endothelial growth factor receptor (VEGFR) and the insulin-like growth factor 1 receptor (IGF1R). The latter is part of the insulin and insulin-like growth factor (IGF) family that includes three ligands (insulin, IGF-I and IGF-II), different cell surface receptors (the insulin receptor, the IGF-IR, IGF-IIR and hybrid heterodimer receptors between the insulin receptor and IGF-IR) and six IGF-binding proteins (IGFBP 1 to 6). This complex system promotes the release of IGFs modulating their interaction with receptors and different IGFBP proteases (12-15).

In the extracellular compartment, insulin and IGFs activate intracellular signaling pathways by binding-with different affinity-their cognate and/or non-cognate receptors. The interaction between ligands and receptors results in the recruitment of downstream insulin receptor substrates (IRSs) and SRC homologous and collagen-like (SHC) proteins. These cytoplasmatic proteins modulate the activation of the PI3K/ $\mathrm{AKT} / \mathrm{mTOR}$ axis and the RAS/RAF/MEK/ERK pathway involved in the transcription of genes regulating cell proliferation, cell-cycle progression, cell motility and apoptosis (16).

Aberrant activation of the Insulin/IGF signaling plays a crucial role in dysregulation of multiple cellular pathways in different tumors and its atypical activation is usually associated with a poor prognosis (17-21).

In the present review we summarize current research on the role of the IGF system in the pathogenesis of GBM and discuss the clinical significance and therapeutic implications of this pathway in the development of resistance to both currently approved and experimental treatments.

\section{EXPRESSION OF IGF SYSTEM COMPONENTS IN GBM}

Studies on the expression of Insulin/IGF system components in human GMB samples are often conflicting and depend on the detection technique employed.

Use of in situ hybridization (ISH) or immunohistochemistry (IHC) techniques for the detection of IGF-I and II revealed high levels of these two ligands in GBM samples compared to normal glial tissue (22-25). On the contrary, analyses conducted by realtime PCR on tissue microarrays showed no change in IGF-I or IGF-II transcripts between normal glial samples and high-grade gliomas, including GBMs $(23,25)$.

Both IGF-IR and IGF-IIR are overexpressed in GBMs compared with normal brain and this overexpression is often associated with inferior survival and a less favorable response to therapy $(23,26)$.

IGFBPs overexpression is also well documented in glioblastoma. Different studies demonstrate that IGFBP-2 is overexpressed in glioma cells showing a distinct progressionrelated expression change from low- to high-grade gliomas (2729). Indeed, high IGFBP-2 levels promote both proliferation and invasion of glioma cells and have been linked to an adverse prognosis in high-grade gliomas (30-32).

IGFBP-3, IGFBP-4 and IGFBP-5 transcripts are significantly higher in GBM compared to low-grade gliomas or normal samples, supporting their role in the pathogenesis of gliomas. Furthermore, IGFBP-4 up-regulation favors epithelialmesenchymal transition (EMT), proliferation, migration and invasion $(29,33,34)$. Unlike other IGFBPs, the expression of IGFBP-6 inversely correlates with glioma grade and higher plasma IGFBP-6 levels have been associated with a better prognosis $(15,35)$.

Therefore, dysregulation of several IGF system components is usually associated with a more aggressive disease displaying poor response to therapy and a shorter survival (15).

\section{THE IGF SIGNALING PATHWAY IN GBM}

IGF-I interaction with IGF-IR appears to trigger low-grade glioma progression to GBM (Figure 1A). Specifically, IGF-IR stimulation by IGF-I promotes glioma cell proliferation and migration by negatively or positively modulating PI3K/AKT signaling through a mechanism conditioned by a specific cellular context $(36,37)$. In a subpopulation of glioma stem cell-like cells identified as recurrence-initiating stem-like cancer (RISC) cells, IGF-IR maintains cell survival through an autocrine activation that downregulates both AKT and ERK signaling leading to slow-growth but high-self-renewal $(38,39)$. On the contrary, this mechanism is not observed in non-glioma stem cells. Furthermore, Hagerstrand and colleagues demonstrated that glioma cells showed ligand-independent AKT phosphorylation and that combined inhibition of IGF-IR and PI3K or mTOR reduces cell viability (37). These data are also supported by recent evidence suggesting that, IGF-I or IGF-IR overexpression causes AKT phosphorylation while its inhibition reduces IGF-mediated antiapoptotic effects (40).

Involvement of the AKT pathway in GBM pathogenesis is also connected to activation of the insulin receptor (InsR) that promotes proliferation and survival of glioma cells both in an insulindependent and -independent manner (Figure 1A). Insulin signaling is robustly activated in human glioma cells independently of insulin stimulation, since the catalytic subunit of the InsR strongly phosphorylates and recruits IRS-1 leading to the activation of AKT and ERK2 (41) (Figure 1A). Furthermore, experiments conducted in insulin-stimulated IRS-1-transfected glioma cell showed high phosphorylation levels of AKT, ERK1/2 and overexpression of Grb2 resulting in increased cell viability (42).

The compensatory mechanism within the InsR/IGF signaling network was widely described in different tumor types $(43,44)$. 
A

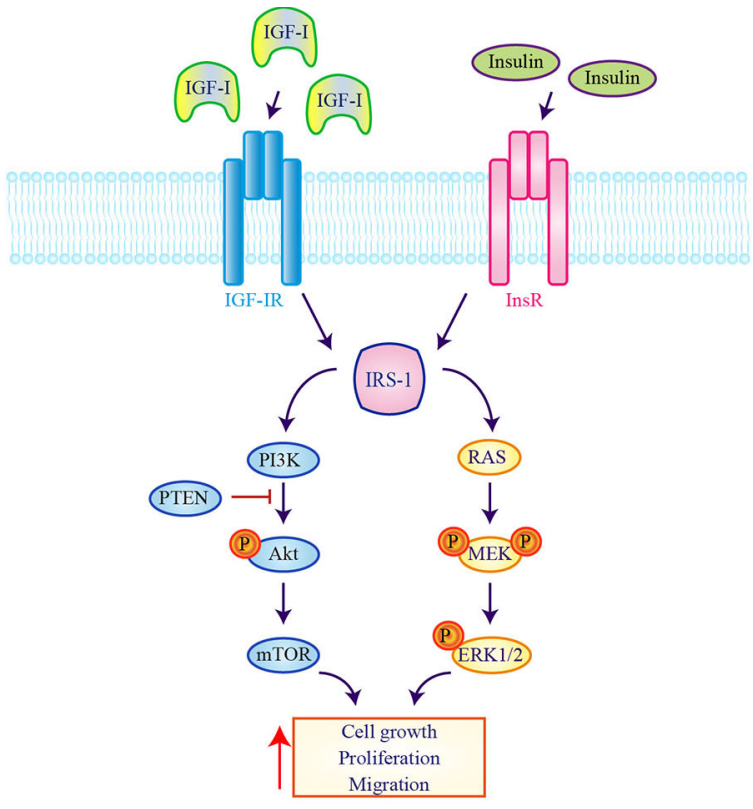

\section{B}
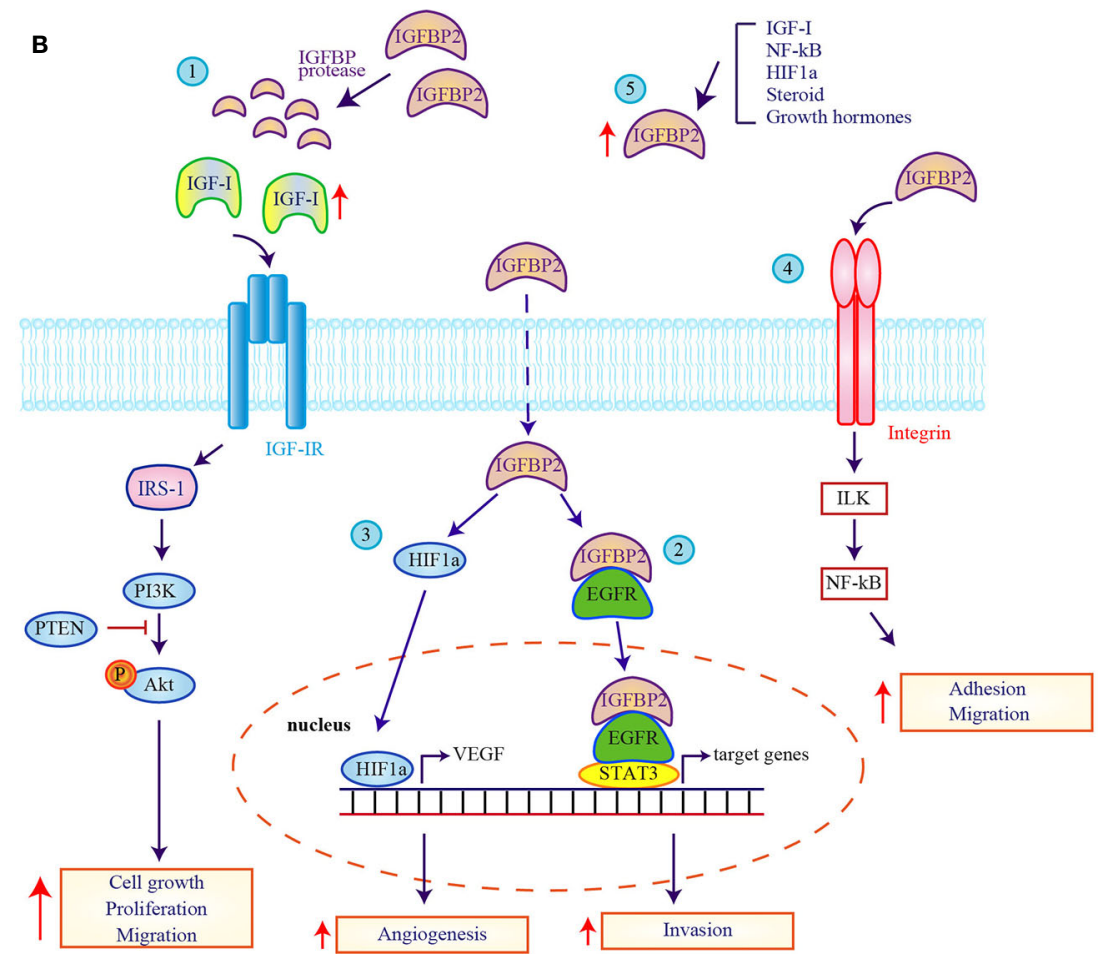

FIGURE 1 | Expression and function of the insulin/insulin-like growth factor system in glioblastoma cells. (A) The pathogenesis and progression of glioblastoma multiforme (GBM) is mainly linked to the activation of Insulin-like growth factor 1 receptor (IGF-IR) and insulin receptor (InsR). The stimulation of IGF-IR and the activation of InsR promote the recruitment of IRS-1 and the activation of the mitogenic and pro-sunvival mediators Akt and ERK1/2 that contribute to increase (upward red arrow) GBM cell growth, cell proliferation and cell migration. (B) A pivotal role in regulating IGF-system action in GBM pathogenesis is provided by IGFBP-2. (1) The improper activity of protease that cleaves IGFBP-2 causes an increase of circulating-free IGFs (upward red arrow) and the subsequent activation of downstream pathway causing an increase on cell growth, cell proliferation and cell migration. The intracytoplasmatic and intranuclear activity of IGFBP-2 determines the activation of EGFR-STAT-3 (2) or HIF1a (3) signaling and the improvement of the transcription of their target genes. IGFBP-2 activates also the integrin signaling (4) which lead to the activation of the IGFBP-2/Integrin/LKNF-kB pathway that is responsible of the transcription of genes linked to adhesion and migration. Finally, stimuli induced by IGF-I, NF-kB, HF1a, steroid and growth hormones (5) increase IGFBP-2 expression (upward red arrow) causing the activation of pathway linked to GBM progression. 
Gong and colleagues found predominant InsR mitogenic isoform-A in GBM surgical specimens and xenograft tumor lines. Interestingly, they observed that InsR-A depletion compromised Akt activation repressing orthotopic tumor growth, but this event has been restored by stimulated IGF-IR expression. These data confirm the cooperation between InsR and IGF-IR also in glioma cells, suggesting a compensatory crosstalk addressed to balance potential defective activity in one of two signaling (45).

Crosstalk between InsR/IGF systems and other RTK pathways has been demonstrated in many human cancers, including GBM (46-50). It was reported that Hedgehog-IGF-I crosstalk preserves the self-renewal properties in GBM. This interaction causes VEGF expression and increases survival and proliferation in Glioma Stem Cell (GSC) involving Gli1 but not Gli2 proteins $(51,52)$. A crosstalk between InsR/IGF-IR and EGFR linked to an Akt-mediated compensatory intracellular mechanism was also described (53).

IGFBPs have multiple and complex functions playing a pivotal and significant role in regulating IGF-system action in GBM. Different authors reported IGFBP-2 as central mediators in GBM pathogenesis and two controversial mechanisms have been hypothesized (Figure 1B). The first one includes an improper protease activity of IGFBP-2 that determines an increase of circulating-free IGFs and the activation of EGFRSTAT3 signaling in an IGF-independent manner, involving the intracytoplasmic and intranuclear IGFBP2 functions (54). The second mechanism is more complex. In GBM cells IGFBP-2 expression is inversely correlated with PTEN levels, thus promoting Akt-mediated signaling. In addition, stimuli induced by IGF-I, NF-kB, hypoxia-inducible factor 1a (HIF1a), steroid and growth hormones increase IGFBP-2 expression eventually causing GBM progression. Furthermore, increased IGFBP-2 levels have been directly associated to enhanced cell proliferation and correlates with HIF1a-mediated stimulation of VEGF pathway (55). Moreover, IGFBP-2 and integrin alpha5 interaction seem necessary to promote glioma cell migration in a JNK-dependent manner (56). Finally, IGFBP-2 was also identified as critical component of a complex network (IGFBP2/Integrin/Integrin-Linked Kinase (ILK)/NF-kB) able to drive glioma progression. Kristen and colleagues proposed that IGFBP-2 is request for the formation of integrin complex which lead to ILK and NF-kB activation responsible of diffuse glioma progression (27).

As well as IGFBP-2, also IGFBP-3 improves glioma cell migration, invasion and proliferation in an IGF-independent manner. The tumor promoting properties of IGFBP-3 are linked to its ability to increase STAT-1 expression that, in turn, result associated with reduced patients overall survival (OS) (57). Furthermore, Chia-Hua Chen demonstrated that IGFBP-3 silencing suppresses glioma cell proliferation by $\mathrm{G} 2 / \mathrm{M}$ cell cycle arrest (58). On the contrary, the anti-tumorigenic and anti-angiogenetic functions of IGFBP-4 in glioma cells depend to its ability to induce dibutyryl cyclic AMP (dB-cAMP) that antagonize the VEGFs action in an IGF-independent manner (59).
IGFBP-5 is highly expressed in GBM, indeed its depletion results in an inhibition of cell invasion and concomitant increase in cell proliferation. The double role of IGFBP-5 is mechanistically associated with Akt and EMT signaling (60).

Lastly, IGFBP-6 is a member of a paracrine signaling circuit involving the IGF-II-IGF-IR axis present in TMZ-resistant glioma cells. IGFBP-6, released by TMZ-sensitive cells, reduces the expansion of the counterpart resistant cell population by sequestering IGF-II that results in IGF-IR-Akt signaling inactivation (15).

\section{MicroRNAs AS REGULATORS OF THE IGF SYSTEM IN GBM}

MicroRNAs (miRNAs) are a class of small non-coding RNAs that are usually classified into tumor-suppressive miRNAs (TSmiRNAs) and onco-miRNAs depending on their ability to suppress or favor tumorigenesis. MiRNA dysregulation is associated with initiation and progression of several forms of cancer, including $\operatorname{GBM}(61,62)$.

It has been reported that miRNA miR-128, miR-422a and miR-603 inhibit IGF-I expression in glioma cells as overexpression of these miRNAs suppresses cell proliferation, migration and invasion (63) and enhances apoptotic death through the inhibition of the mTOR signaling pathway (64). Furthermore, a plethora of TS-miRNAs (including miR-7, miR15b, miR-181b, miR-186, miR-320a, miRNA-323-5p, miR-383, miR-422a, miR-503, miR-505, and miR603) target IGF-IR messenger RNA in the non-neoplastic brain, thereby acting as tumor-suppressors. In GBM the expression of these miRNAs is reduced resulting in activation of the IGF-IR/AKT axis. In vitro studies demonstrated that TS-miRNAs overexpression also induces cell-cycle arrest and apoptosis (63, 65-74). Several miRNAs modulate IGF/IGF-IR signaling by targeting its downstream effectors. Indeed, miR-204-3p and miR-491-3p inhibit IGFBP-2 expression and are downregulated in glioma cells $(75,76)$. MiR-302b indirectly inhibits IGFBP-2 activity by downregulating the expression of its direct target Nuclear factor IA (NFIA), which transcriptionally regulates IGFBP-2 expression (77). MiR-7 potently inhibits EGFR, IRS-1 and IRS2 expression (78), while the brain-specific miR-153 downregulates IRS-2 (79). Moreover, the tumor suppressor miR-128-3p indirectly regulates IRS-1 expression by modulating the expression of Neuronal Pentraxin 1 situated upstream of the IRS-1/PI3K/AKT pathway (80). The reported downregulation of these TS-miRNAs in malignant glioma results in IRS overexpression and activation of the PI3K/AKT pathway $(78,79)$.

Finally, among the onco-miRNAs, only miR-21 and miR513a-5p are overexpressed in human GBM cell lines and tumor tissue $(81,82)$. Yang and colleagues reported that high levels of miR-21 lead to downregulation of IGFBP-3, restraining its antiproliferative activity. Interestingly, miR-21 expression levels are inversely correlated with GBM survival (82). 


\section{THE IGF SYSTEM AND TREATMENT RESISTANCE IN GBM}

Several pre-clinical evidences suggest that the IGF system plays a pivotal role in the development of resistance to chemotherapy, radiation and targeted therapies, eventually resulting in GBM recurrence and/or progression (83).

Differences in both protein expression and miRNA production related to the IGF pathway have been found in TMZ-sensitive and -resistant GBM cells. These differences could be exploited to restore chemo-sensitivity in resistant cells. Indeed, compared with TMZ-sensitive malignant glioma cells, the resistant ones express higher miR-497 levels. This difference may play a role in the induction of TMZ resistance through the activation of the IGF-IR/IRS-1 pathway-related proteins, that are IGF-IR, IRS1, mTOR and Bcl-2 (84). Furthermore, TMZ-resistant cells display lower IGFBP-6 expression than TMZ-sensitive cells, with the latter downregulating both IGF-II and IGF-IR as IGFBP-6 acts as a suicide substrate binding IGF-II with high affinity and preventing its interaction with IGF-IR. Although the site of IGFBP-6 endogenous production remains unclear, this model suggests a paracrine secretion from TMZ-sensitive cells. Hence, by depleting the sensitive population, TMZ selects the resistant one, ultimately promoting growth of the tumor mass $(15,84)$. The IGF-system also seems to determine resistance to alkylating agents through a miRNA-mediated activation of $\mathrm{WNT} / \beta$ catenin signaling. In detail, IGF-I up-regulates miR-513a-5p, which in turn represses NEural precursor cell-expressed Developmentally Downregulated 4-Like (NEDD4L), ultimately leading to $\mathrm{WNT} / \beta$-catenin activation (81). $N E D D 4 L$ is a tumor suppressor gene encoding for a ubiquitine ligase, which regulates ion channel expression and intracellular signaling (85). Indeed, low NEDD4L levels correlate with TMZ resistance and poor prognosis in gliomas (86).

The induction of a stem-cell phenotype is one of the main causes of resistance to radiation therapy in GBM. IGF signaling is involved in this process trough mechanisms only partially understood $(39,87)$. MiR-603 targets IGF-I and IGF-IR, facilitating the exit from the stem-cell condition and conferring sensitivity toward radiation. However, ionizing radiation reduces miR-603 expression by enhancing its extracellular vesiclemediated export. Hence, lower levels of MiR-603 induced by radiotherapy may promote a stem-cell state. miR-603 also suppresses O6-MethylGuanine-DNA-MethylTransferase (MGMT). Consequently, decreased miR-603 activity determines MGMT up-regulation, which ultimately leads to cross-resistance toward alkylating agents in glioma cells (74). Recently, Simpson et al. further supported the involvement of the IGF-IR in the radiation resistance of high grade gliomas describing radio-sensitization after IGF-IR inhibition in pediatric patients (88).

Even though the EGFR represents a potential target for GBM treatment, its inhibition led to dismal results due to intrinsic tumor resistance to this approach $(89,90)$. Indeed, activation of a compensatory IGF pathway exerts a pivotal role in the lack of sensitivity toward EGFR inhibition. Simultaneous targeting of the EGFR and IGF-IR was effective in GBM cell lines and patient derived xenografts (PDX) $(53,91)$. On a different note, miR-7 overexpression sensitizes GBM cells to the antitumor effect of erlotinib via blockage of the IRS/AKT pathway (92). Thus, quantification of IGF-IR tissue levels may be employed as a predictive biomarker to improve the selection of GBM patients likely to benefit from EGFR inhibitors as reported in the NCT00897663 trial.

The PDGFR is another RTK involved in gliomas development. As for EGFR, PDGFR inhibition has marginal activity in GBM $(89,93,94)$. Again, the InsR and IGF-IR seem key effectors of resistance to PDGFR inhibitors and combining an anti-PDGFR and an anti IGF-IR decrease the viability of primary mouse tumor sphere PDGFR-resistant clones obtained from glioma samples in vitro (95).

Inhibition of key components within the GBM tumor microenvironment may also represent an attractive strategy. To this end, colony-stimulating factor-1 receptor (CSF-1R) inhibitors, which block the tumor-associated macrophages and microglia, are currently under development $(96,97)$. Quail and colleagues investigated the mechanism of resistance to CSF-1R inhibition in murine models of GBM, discovering that it is mediated by activation of the PI3K pathway via the IGF-I/IGF-IR system. Hence, coupling CSF-1R and PI3K or IGF-IR inhibition elicits a sustained response in mice (98).

Recently, a molecule targeting the sarcoendoplasmic reticulum $\mathrm{Ca} 2+$ ATPase (SERCA) has been tested on patientderived GBM neurospheres, identifying responder and nonresponder cell lines. The latter seem to bypass SERCA activity via a mechanism mediated by IRE1 (derived from ERN1 gene), IGFBP-3 and IGFBP-5. Indeed, CRISPR-mediated deletion of the ERN1, IGFBP3, IGFBP5 genes in a human GBM cell line increased responsiveness to drugs (99).

\section{ANTI-IGF THERAPEUTIC STRATEGIES IN GBM}

Despite the many advances in the field of molecular targeted therapy, the use of small molecules agents or monoclonal antibodies for the treatment of GBM is extremely limited and some promising pre-clinical results have yet to translate into meaningful therapeutic benefits (100-103).

Many approaches have been tested to inhibit IGF signaling in GBM including anti-sense oligonucleotides, tyrosine kinase inhibitors (TKIs) or monoclonal antibodies targeting the IGFIR (Figure 2). In a pilot study, inhibition of IGF-IR expression by antisense strategy failed to produce any clinical benefit for patients with recurrent GBM (104). An improvement was obtained by employing the combination of IGF-I antisense/ triple helix vector strategy to create immunogenic cells that were injected in GBM patients where they induced an antitumor immune response and stopped tumor progression. The survival of two treated GBM patients reached 2 years $(105,106)$. 


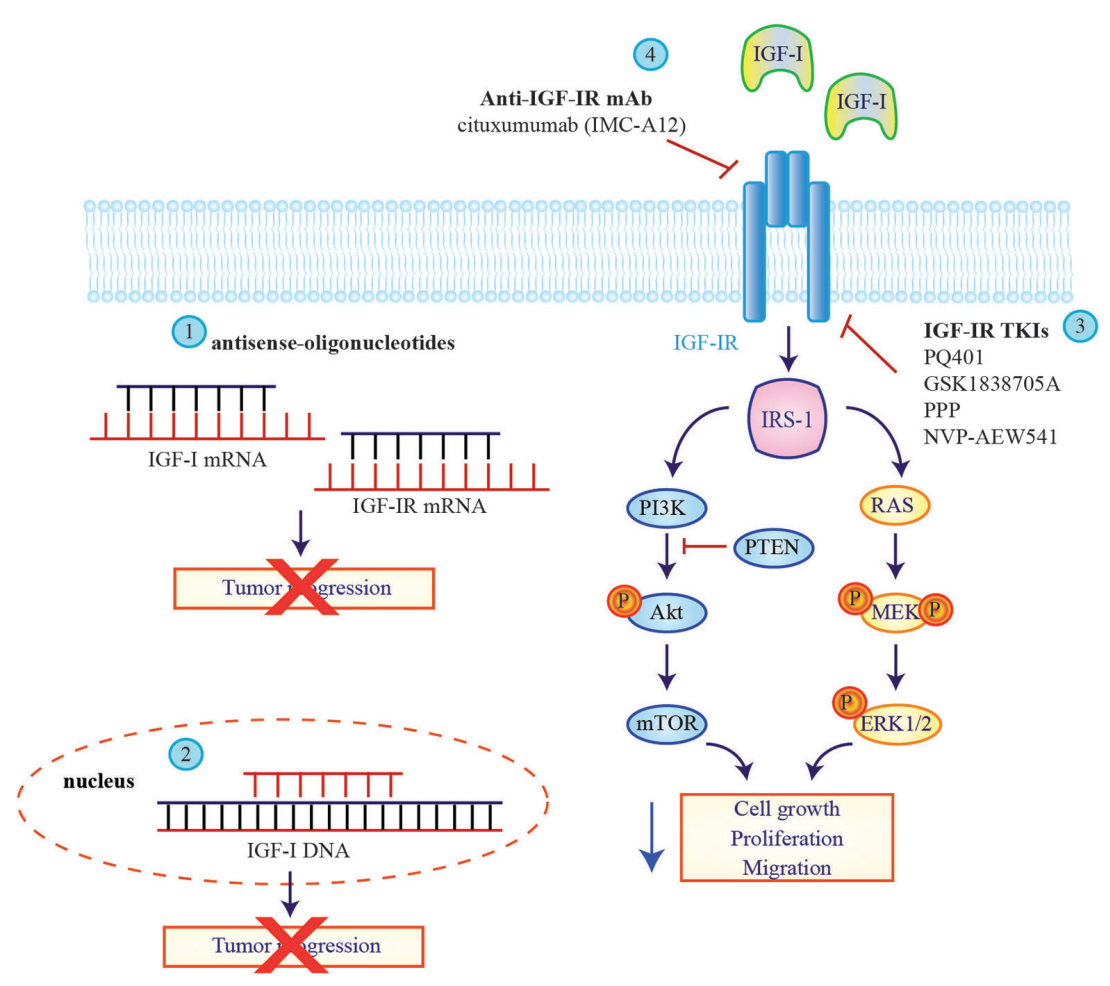

FIGURE 2 | Therapeutic strategies to block insulin-like growth factor signaling in glioblastoma multiforme cells. Approaches tested to inhibit insulin-like growth factor (IGF) signaling in glioblastoma (GBM) patients include antisense oligonucleotides against IGF-I and IGF-IR mRNA (1) or the employ of IGF-I triple helix gene therapy (2) to induce a block of tumor progression. IGF-IR direct inhibitors, IGF-IR TKIs (3) and IGF-IR mAbs (4) are also tested on GBM cell lines to reduce IGF downstream signaling.

Promising results were also obtained with a treatment based on autologous glioma cells treated ex vivo with an antisense oligodeoxynucleotide targeting the IGF-IR (IGF-1R/AS ODN) and re-implanted in patients. Seventeen out of 33 individuals enrolled in a phase Ib trial (NCT02507583) remained progression-free and 12 of them are still alive, demonstrating that an autologous cell vaccine may significantly prolong progression free survival (PFS) and OS compared to standard of care (107).

Several IGF-IR-directed TKIs have been tested in GBM patients with promising pre-clinical results. PQ401, GSK1838705A and PPP (picropodophyllin/AXL1717) all reduced cell viability and proliferation in vitro, while the administration in mice led to inhibition of glioma tumor growth in vivo $(26,108,109)$. Notably PPP causes dramatic tumor regression not only in subcutaneous but also in intracerebral xenograft models, indicating that it crosses the blood-brain barrier. Hence a phase I/II clinical trial was initiated (NCT101721577) but results have not yet been posted. NVP-AEW541 is another IGF-IR-specific TKI that in combination with dasatinib significantly increases BAX activation inducing more apoptosis than either agent alone in glioma cells (110).

Multiple IGF-IR blocking antibodies are currently in clinical development (111) but - to date - only cixutumumab (IMC-A12) has been clinically tested on patients diagnosed with GBM.
Cixutumumab binds IGF-IR or IGF-IR/IR hybrid receptors blocking the interaction with their ligands and inducing receptor internalization and degradation. Zamykal and colleagues demonstrated that cixutumumab inhibits GBM progression in in vivo xenograft models (112). A phase I study of IMC-A12 in combination with temsirolimus was also conducted in a group of pediatric patients including four with refractory GBM demonstrating that this combination was well tolerated (113). However these results were deemed insufficient to pursue further development of this compound.

\section{CONCLUSIONS}

GBM is an aggressive disease, with a dismal prognosis and scarce therapeutic resources. Hence, understanding the biological features underlying disease pathogenesis, maintenance and progression represents urgent and unmet medical need. To date, a plethora of pre-clinical evidence demonstrates a crucial role for the IGF system in GBM. Altered IGF signaling as well as cross-talk with multiple pathways are complex and far from being fully understood. However, the IGF system could potentially be exploited for both diagnostic and therapeutic purposes. For example, the expression level of many components of the IGF signaling axis or their serum concentration in GBM patients may become prognostic biomarkers, eventually guiding therapeutic choices. Unfortunately, thus far the 
clinical efficacy of treatment strategies directed against the IGF system remains limited and inconsistent. Inter- and intra-tumor heterogeneity, cross talk between IGF and RTK signaling and limited drug distribution to the central nervous system, are some of the potential reasons for the lack of substantial anti-cancer activity. Hence, further development of innovative therapeutic approaches is warranted in order to expand the therapeutic armamentarium for GBM patients.

\section{REFERENCES}

1. Weller M, Wick W, Aldape K, Brada M, Berger M, Pfister SM, et al. Glioma. Nat Rev Dis Primers (2015) 1:15017. doi: 10.1038/nrdp.2015.17

2. Ostrom QT, Cote DJ, Ascha M, Kruchko C, Barnholtz-Sloan JS. Adult Glioma Incidence and Survival by Race or Ethnicity in the United States From 2000 to 2014. JAMA Oncol (2018) 4(9):1254-62. doi: 10.1001/ jamaoncol.2018.1789

3. Davis ME, Stoiber AM. Glioblastoma multiforme: enhancing survival and quality of life. Clin J Oncol Nurs (2011) 15(3):291-7. doi: 10.1188/ 11.CJON.291-297

4. Ostrom QT, Gittleman H, Farah P, Ondracek A, Chen Y, Wolinsky Y, et al. CBTRUS statistical report: Primary brain and central nervous system tumors diagnosed in the United States in 2006-2010. Neuro Oncol (2013) 15 Suppl 2:ii1-56. doi: 10.1093/neuonc/not151

5. Tan AC, Ashley DM, Lopez GY, Malinzak M, Friedman HS, Khasraw M. Management of glioblastoma: State of the art and future directions. CA Cancer J Clin (2020) 70(4):299-312. doi: 10.3322/caac.21613

6. Kim G, Ko YT. Small molecule tyrosine kinase inhibitors in glioblastoma. Arch Pharm Res (2020) 43(4):385-94. doi: 10.1007/s12272-020-01232-3

7. Lee A, Arasaratnam M, Chan DLH, Khasraw M, Howell VM, Wheeler H. Anti-epidermal growth factor receptor therapy for glioblastoma in adults. Cochrane Database Syst Rev (2020) 5:CD013238. doi: 10.1002/ 14651858.CD013238.pub2

8. Phillips HS, Kharbanda S, Chen R, Forrest WF, Soriano RH, Wu TD, et al. Molecular subclasses of high-grade glioma predict prognosis, delineate a pattern of disease progression, and resemble stages in neurogenesis. Cancer Cell (2006) 9(3):157-73. doi: 10.1016/j.ccr.2006.02.019

9. Qazi MA, Vora P, Venugopal C, Sidhu SS, Moffat J, Swanton C, et al. Intratumoral heterogeneity: pathways to treatment resistance and relapse in human glioblastoma. Ann Oncol (2017) 28(7):1448-56. doi: 10.1093/ annonc/mdx169

10. Parsons DW, Jones S, Zhang X, Lin JC, Leary RJ, Angenendt P, et al. An integrated genomic analysis of human glioblastoma multiforme. Science (2008) 321(5897):1807-12. doi: 10.1126/science.1164382

11. Cancer Genome Atlas Research N. Comprehensive genomic characterization defines human glioblastoma genes and core pathways. Nature (2008) 455(7216):1061-8. doi: 10.1038/nature07385

12. Bunn RC, Fowlkes JL. Insulin-like growth factor binding protein proteolysis. Trends Endocrinol Metab (2003) 14(4):176-81. doi: 10.1016/s1043-2760(03) 00049-3

13. Jin L, Shen F, Weinfeld M, Sergi C. Insulin Growth Factor Binding Protein 7 (IGFBP7)-Related Cancer and IGFBP3 and IGFBP7 Crosstalk. Front Oncol (2020) 10:727:727. doi: 10.3389/fonc.2020.00727

14. Allard JB, Duan C. IGF-Binding Proteins: Why Do They Exist and Why Are There So Many? Front Endocrinol (Lausanne) (2018) 9:117:117. doi: $10.3389 /$ fendo. 2018.00117

15. Oliva CR, Halloran B, Hjelmeland AB, Vazquez A, Bailey SM, Sarkaria JN, et al. IGFBP6 controls the expansion of chemoresistant glioblastoma through paracrine IGF2/IGF-1R signaling. Cell Commun Signal (2018) 16 (1):61. doi: 10.1186/s12964-018-0273-7

16. Hakuno F, Takahashi SI. IGF1 receptor signaling pathways. J Mol Endocrinol (2018) 61(1):T69-86. doi: 10.1530/JME-17-0311

17. Bowers LW, Rossi EL, O'Flanagan CH, deGraffenried LA, Hursting SD. The Role of the Insulin/IGF System in Cancer: Lessons Learned from Clinical

\section{AUTHOR CONTRIBUTIONS}

Conceptualization, ET and MM. Formal analysis, ET and SG. Data curation, ET and CT. Writing-original draft preparation, ET, MM, MP, SS, FM, GP, CR, AP, and LM. Writing-review and editing, ET, MM, MP, SS, FM, AP, GP, CR, SV, and LM. Supervision, PV. All authors contributed to the article and approved the submitted version.

Trials and the Energy Balance-Cancer Link. Front Endocrinol (Lausanne) (2015) 6:77:77. doi: 10.3389/fendo.2015.00077

18. Sachdev D, Yee D. The IGF system and breast cancer. Endocr Relat Cancer (2001) 8(3):197-209. doi: 10.1677/erc.0.0080197

19. Vigneri PG, Tirrò E, Pennisi MS, Massimino M, Stella S, Romano C, et al. The Insulin/IGF System in Colorectal Cancer Development and Resistance to Therapy. Front Oncol (2015) 5:230:230. doi: 10.3389/fonc.2015.00230

20. Yu H, Rohan T. Role of the insulin-like growth factor family in cancer development and progression. J Natl Cancer Inst (2000) 92(18):1472-89. doi: $10.1093 /$ jnci/92.18.1472

21. Pearson JRD, Regad T. Targeting cellular pathways in glioblastoma multiforme. Signal Transd Targ Ther (2017) 2:17040. doi: 10.1038/ sigtrans.2017.40

22. Hirano H, Lopes MB, Laws ERJr., Asakura T, Goto M, Carpenter JE, et al. Insulin-like growth factor-1 content and pattern of expression correlates with histopathologic grade in diffusely infiltrating astrocytomas. Neuro Oncol (1999) 1(2):109-19. doi: 10.1093/neuonc/1.2.109

23. Maris C, D’Haene N, Trepant AL, Le Mercier M, Sauvage S, Allard J, et al. IGF-IR: a new prognostic biomarker for human glioblastoma. Br J Cancer (2015) 113(5):729-37. doi: 10.1038/bjc.2015.242

24. Soroceanu L, Kharbanda S, Chen R, Soriano RH, Aldape K, Misra A, et al. Identification of IGF2 signaling through phosphoinositide-3-kinase regulatory subunit 3 as a growth-promoting axis in glioblastoma. Proc Natl Acad Sci U.S.A. (2007) 104(9):3466-71. doi: 10.1073/pnas.0611271104

25. Suvasini R, Shruti B, Thota B, Shinde SV, Friedmann-Morvinski D, Nawaz $\mathrm{Z}$, et al. Insulin growth factor-2 binding protein 3 (IGF2BP3) is a glioblastoma-specific marker that activates phosphatidylinositol 3-kinase/ mitogen-activated protein kinase (PI3K/MAPK) pathways by modulating IGF-2. J Biol Chem (2011) 286(29):25882-90. doi: 10.1074/jbc.M110.178012

26. Yin S, Girnita A, Stromberg T, Khan Z, Andersson S, Zheng $\mathrm{H}$, et al. Targeting the insulin-like growth factor-1 receptor by picropodophyllin as a treatment option for glioblastoma. Neuro Oncol (2010) 12(1):19-27. doi: 10.1093/neuonc/nop008

27. Holmes KM, Annala M, Chua CY, Dunlap SM, Liu Y, Hugen N, et al Insulin-like growth factor-binding protein 2-driven glioma progression is prevented by blocking a clinically significant integrin, integrin-linked kinase, and NF-kappaB network. Proc Natl Acad Sci U.S.A. (2012) 109(9):3475-80. doi: $10.1073 /$ pnas.1120375109

28. Sallinen SL, Sallinen PK, Haapasalo HK, Helin HJ, Helen PT, Schraml P et al. Identification of differentially expressed genes in human gliomas by DNA microarray and tissue chip techniques. Cancer Res (2000) 60 (23):6617-22.

29. Santosh V, Arivazhagan A, Sreekanthreddy P, Srinivasan H, Thota B, Srividya MR, et al. Grade-specific expression of insulin-like growth factorbinding proteins $-2,-3$, and -5 in astrocytomas: IGFBP-3 emerges as a strong predictor of survival in patients with newly diagnosed glioblastoma. Cancer Epidemiol Biomarkers Prev (2010) 19(6):1399-408. doi: 10.1158/10559965.EPI-09-1213

30. Lin Y, Jiang T, Zhou K, Xu L, Chen B, Li G, et al. Plasma IGFBP-2 levels predict clinical outcomes of patients with high-grade gliomas. Neuro Oncol (2009) 11(5):468-76. doi: 10.1215/15228517-2008-114

31. McDonald KL, O'Sullivan MG, Parkinson JF, Shaw JM, Payne CA, Brewer JM, et al. IQGAP1 and IGFBP2: valuable biomarkers for determining prognosis in glioma patients. J Neuropathol Exp Neurol (2007) 66(5):40517. doi: $10.1097 /$ nen $0 \mathrm{~b} 013 \mathrm{e} 31804567 \mathrm{~d} 7$ 
32. Wang H, Wang H, Shen W, Huang H, Hu L, Ramdas L, et al. Insulin-like growth factor binding protein 2 enhances glioblastoma invasion by activating invasion-enhancing genes. Cancer Res (2003) 63(15):4315-21.

33. Jiang R, Mircean C, Shmulevich I, Cogdell D, Jia Y, Tabus I, et al. Pathway alterations during glioma progression revealed by reverse phase protein lysate arrays. Proteomics (2006) 6(10):2964-71. doi: 10.1002/ pmic. 200500555

34. Praveen Kumar VR, Sehgal P, Thota B, Patil S, Santosh V, Kondaiah P. Insulin like growth factor binding protein 4 promotes GBM progression and regulates key factors involved in EMT and invasion. J Neurooncol (2014) 116 (3):455-64. doi: 10.1007/s11060-013-1324-y

35. Bei Y, Huang Q, Shen J, Shi J, Shen C, Xu P, et al. IGFBP6 Regulates Cell Apoptosis and Migration in Glioma. Cell Mol Neurobiol (2017) 37(5):88998. doi: 10.1007/s10571-016-0426-4

36. Schlenska-Lange A, Knupfer H, Lange TJ, Kiess W, Knupfer M. Cell proliferation and migration in glioblastoma multiforme cell lines are influenced by insulin-like growth factor I in vitro. Anticancer Res (2008) 28(2A):1055-60.

37. Hagerstrand D, Lindh MB, Pena C, Garcia-Echeverria C, Nister M, Hofmann F, et al. PI3K/PTEN/Akt pathway status affects the sensitivity of high-grade glioma cell cultures to the insulin-like growth factor-1 receptor inhibitor NVP-AEW541. Neuro Oncol (2010) 12(9):967-75. doi: 10.1093/ neuonc/noq029

38. Osuka S, Sampetrean O, Shimizu T, Saga I, Onishi N, Sugihara E, et al. IGF1 receptor signaling regulates adaptive radioprotection in glioma stem cells. Stem Cells (2013) 31(4):627-40. doi: 10.1002/stem.1328

39. Osuka S, Van Meir EG. Overcoming therapeutic resistance in glioblastoma: the way forward. J Clin Invest (2017) 127(2):415-26. doi: $10.1172 /$ JCI89587

40. Zhang M, Liu J, Li M, Zhang S, Lu Y, Liang Y, et al. Insulin-like growth factor 1/insulin-like growth factor 1 receptor signaling protects against cell apoptosis through the PI3K/AKT pathway in glioblastoma cells. Exp Ther Med (2018) 16(2):1477-82. doi: 10.3892/etm.2018.6336

41. Pei Z, Lee KC, Khan A, Wang HY. Hyperactivated Insulin Signaling Cascade in Human Glioblastoma Cells. Crit Rev Oncog (2019) 24(3):243-50. doi: 10.1615/CritRevOncog.2019031365

42. Gorgisen G, Yaren Z. Insulin receptor substrate 1 overexpression promotes survival of glioblastoma cells through AKT1 activation. Folia Neuropathol (2020) 58(1):38-44. doi: 10.5114/fn.2020.94005

43. Buck E, Gokhale PC, Koujak S, Brown E, Eyzaguirre A, Tao N, et al. Compensatory insulin receptor (IR) activation on inhibition of insulin-like growth factor-1 receptor (IGF-1R): rationale for cotargeting IGF-1R and IR in cancer. Mol Cancer Ther (2010) 9(10):2652-64. doi: 10.1158/15357163.MCT-10-0318

44. Zhang H, Pelzer AM, Kiang DT, Yee D. Down-regulation of type I insulinlike growth factor receptor increases sensitivity of breast cancer cells to insulin. Cancer Res (2007) 67(1):391-7. doi: 10.1158/0008-5472.CAN-061712

45. Gong Y, Ma Y, Sinyuk M, Loganathan S, Thompson RC, Sarkaria JN, et al. Insulin-mediated signaling promotes proliferation and survival of glioblastoma through Akt activation. Neuro Oncol (2016) 18(1):48-57. doi: 10.1093/neuonc/nov096

46. Liu C, Zhang Z, Tang H, Jiang Z, You L, Liao Y. Crosstalk between IGF-1R and other tumor promoting pathways. Curr Pharm Des (2014) 20(17):291221. doi: 10.2174/13816128113199990596

47. Manzella L, Massimino M, Stella S, Tirrò E, Pennisi MS, Martorana F, et al. Activation of the IGF Axis in Thyroid Cancer: Implications for Tumorigenesis and Treatment. Int J Mol Sci (2019) 20(13):3258-76. doi: 10.3390/ijms20133258

48. Mauro L, Naimo GD, Ricchio E, Panno ML, Ando S. Cross-Talk between Adiponectin and IGF-IR in Breast Cancer. Front Oncol (2015) 5:157:157. doi: 10.3389/fonc.2015.00157

49. Vella V, Malaguarnera R, Nicolosi ML, Palladino C, Spoleti C, Massimino $\mathrm{M}$, et al. Discoidin domain receptor 1 modulates insulin receptor signaling and biological responses in breast cancer cells. Oncotarget (2017) 8 (26):43248-70. doi: 10.18632/oncotarget.18020

50. Vella V, Nicolosi ML, Cantafio P, Massimino M, Lappano R, Vigneri P, et al. DDR1 regulates thyroid cancer cell differentiation via IGF-2/IR-A autocrine signaling loop. Endocr Relat Cancer (2019) 26(1):197-214. doi: 10.1530/ ERC-18-0310

51. Hsieh A, Ellsworth R, Hsieh D. Hedgehog/GLI1 regulates IGF dependent malignant behaviors in glioma stem cells. J Cell Physiol (2011) 226(4):111827. doi: $10.1002 /$ jcp. 22433

52. Santoni M, Burattini L, Nabissi M, Morelli MB, Berardi R, Santoni G, et al. Essential role of Gli proteins in glioblastoma multiforme. Curr Protein Pept Sci (2013) 14(2):133-40. doi: 10.2174/1389203711314020005

53. Ma Y, Tang N, Thompson RC, Mobley BC, Clark SW, Sarkaria JN, et al. InsR/IGF1R Pathway Mediates Resistance to EGFR Inhibitors in Glioblastoma. Clin Cancer Res (2016) 22(7):1767-76. doi: 10.1158/10780432.CCR-15-1677

54. Chua CY, Liu Y, Granberg KJ, Hu L, Haapasalo H, Annala MJ, et al. IGFBP2 potentiates nuclear EGFR-STAT3 signaling. Oncogene (2016) 35(6):738-47. doi: 10.1038 /onc.2015.131

55. Fukushima T, Kataoka H. Roles of insulin-like growth factor binding protein-2 (IGFBP-2) in glioblastoma. Anticancer Res (2007) 27(6A):368592.

56. Mendes KN, Wang GK, Fuller GN, Zhang W. JNK mediates insulin-like growth factor binding protein 2/integrin alpha5-dependent glioma cell migration. Int J Oncol (2010) 37(1):143-53. doi: 10.3892/ijo_00000662

57. Thota B, Arimappamagan A, Kandavel T, Shastry AH, Pandey P, Chandramouli BA, et al. STAT-1 expression is regulated by IGFBP-3 in malignant glioma cells and is a strong predictor of poor survival in patients with glioblastoma. J Neurosurg (2014) 121(2):374-83. doi: 10.3171/ 2014.4.JNS131198

58. Chen CH, Chen PY, Lin YY, Feng LY, Chen SH, Chen CY, et al. Suppression of tumor growth via IGFBP3 depletion as a potential treatment in glioma. $J$ Neurosurg (2019) 132(1):168-79. doi: 10.3171/2018.8.JNS181217

59. Moreno MJ, Ball M, Andrade MF, McDermid A, Stanimirovic DB. Insulinlike growth factor binding protein-4 (IGFBP-4) is a novel anti-angiogenic and anti-tumorigenic mediator secreted by dibutyryl cyclic AMP (dBcAMP)-differentiated glioblastoma cells. Glia (2006) 53(8):845-57. doi: 10.1002/glia.20345

60. Dong C, Zhang J, Fang S, Liu F. IGFBP5 increases cell invasion and inhibits cell proliferation by EMT and Akt signaling pathway in Glioblastoma multiforme cells. Cell Div (2020) 15:4. doi: 10.1186/s13008-020-00061-6

61. Banelli B, Forlani A, Allemanni G, Morabito A, Pistillo MP, Romani M. MicroRNA in Glioblastoma: An Overview. Int J Genomics (2017) 2017:7639084. doi: 10.1155/2017/7639084

62. Luo JW, Wang X, Yang Y, Mao Q. Role of micro-RNA (miRNA) in pathogenesis of glioblastoma. Eur Rev Med Pharmacol Sci (2015) 19 (9):1630-9.

63. Wang $\mathrm{H}$, Tang $\mathrm{C}, \mathrm{Na}$ M, Ma W, Jiang Z, Gu Y, et al. miR-422a Inhibits Glioma Proliferation and Invasion by Targeting IGF1 and IGF1R. Oncol Res (2017) 25(2):187-94. doi: 10.3727/096504016X14732772150389

64. Chen PH, Cheng CH, Shih CM, Ho KH, Lin CW, Lee CC, et al. The Inhibition of microRNA-128 on IGF-1-Activating mTOR Signaling Involves in Temozolomide-Induced Glioma Cell Apoptotic Death. PloS One (2016) 11(11):e0167096. doi: 10.1371/journal.pone.0167096

65. Guo T, Feng Y, Liu Q, Yang X, Jiang T, Chen Y, et al. MicroRNA-320a suppresses in GBM patients and modulates glioma cell functions by targeting IGF-1R. Tumour Biol (2014) 35(11):11269-75. doi: 10.1007/ s13277-014-2283-4

66. He Z, Cen D, Luo X, Li D, Li P, Liang L, et al. Downregulation of miR-383 promotes glioma cell invasion by targeting insulin-like growth factor 1 receptor. Med Oncol (2013) 30(2):557. doi: 10.1007/s12032-013-0557-0

67. Jiang J, Wang W, Fang D, Jin X, Ding L, Sun X. MicroRNA186 targets IGF1R and exerts tumorsuppressing functions in glioma. Mol Med Rep (2017) 16 (5):7821-8. doi: 10.3892/mmr.2017.7586

68. Shi H, Yang H, Xu S, Zhao Y, Liu J. miR-505 functions as a tumor suppressor in glioma by targeting insulin like growth factor 1 receptor expression. Int $J$ Clin Exp Pathol (2018) 11(9):4405-13.

69. Shi ZM, Wang XF, Qian X, Tao T, Wang L, Chen QD, et al. MiRNA-181b suppresses IGF-1R and functions as a tumor suppressor gene in gliomas. RNA (2013) 19(4):552-60. doi: 10.1261/rna.035972.112

70. Wang B, Sun F, Dong N, Sun Z, Diao Y, Zheng C, et al. MicroRNA-7 directly targets insulin-like growth factor 1 receptor to inhibit cellular growth and 
glucose metabolism in gliomas. Diagn Pathol (2014) 9:211. doi: 10.1186/ s13000-014-0211-y

71. Wang J, Liu H, Tian L, Wang F, Han L, Zhang W, et al. miR-15b Inhibits the Progression of Glioblastoma Cells Through Targeting Insulin-like Growth Factor Receptor 1. Horm Cancer (2017) 8(1):49-57. doi: 10.1007/s12672016-0276-Z

72. Yang HA, Wang X, Ding F, Pang Q. MiRNA-323-5p Promotes U373 Cell Apoptosis by Reducing IGF-1R. Med Sci Monit (2015) 21:3880-6. doi: $10.12659 / \mathrm{msm} .895037$

73. Zhang Y, Chen X, Lian H, Liu J, Zhou B, Han S, et al. MicroRNA-503 acts as a tumor suppressor in glioblastoma for multiple antitumor effects by targeting IGF-1R. Oncol Rep (2014) 31(3):1445-52. doi: 10.3892/ or.2013.2951

74. Ramakrishnan V, Xu B, Akers J, Nguyen T, Ma J, Dhawan S, et al. Radiationinduced extracellular vesicle (EV) release of miR-603 promotes IGF1mediated stem cell state in glioblastomas. EBioMedicine (2020) 55:102736. doi: 10.1016/j.ebiom.2020.102736

75. Chen PH, Chang CK, Shih CM, Cheng CH, Lin CW, Lee CC, et al. The miR204-3p-targeted IGFBP2 pathway is involved in xanthohumol-induced glioma cell apoptotic death. Neuropharmacology (2016) 110(Pt A):362-75. doi: 10.1016/j.neuropharm.2016.07.038

76. Li X, Liu Y, Granberg KJ, Wang Q, Moore LM, Ji P, et al. Two mature products of MIR-491 coordinate to suppress key cancer hallmarks in glioblastoma. Oncogene (2015) 34(13):1619-28. doi: 10.1038/onc.2014.98

77. Lee CC, Chen PH, Ho KH, Shih CM, Cheng CH, Lin CW, et al. The microRNA-302b-inhibited insulin-like growth factor-binding protein 2 signaling pathway induces glioma cell apoptosis by targeting nuclear factor IA. PloS One (2017) 12(3):e0173890. doi: 10.1371/ journal.pone. 0173890

78. Xu J, Liao X, Lu N, Liu W, Wong CW. Chromatin-modifying drugs induce miRNA-153 expression to suppress Irs-2 in glioblastoma cell lines. Int $J$ Cancer (2011) 129(10):2527-31. doi: 10.1002/ijc.25917

79. Kefas B, Godlewski J, Comeau L, Li Y, Abounader R, Hawkinson M, et al. microRNA-7 inhibits the epidermal growth factor receptor and the Akt pathway and is down-regulated in glioblastoma. Cancer Res (2008) 68 (10):3566-72. doi: 10.1158/0008-5472.CAN-07-6639

80. Huo L, Wang B, Zheng M, Zhang Y, Xu J, Yang G, et al. miR-128-3p inhibits glioma cell proliferation and differentiation by targeting NPTX1 through IRS-1/PI3K/AKT signaling pathway. Exp Ther Med (2019) 17(4):2921-30. doi: $10.3892 /$ etm. 2019.7284

81. Chen KC, Chen PH, Ho KH, Shih CM, Chou CM, Cheng CH, et al. IGF-1enhanced miR-513a-5p signaling desensitizes glioma cells to temozolomide by targeting the NEDD4L-inhibited Wnt/beta-catenin pathway. PloS One (2019) 14(12):e0225913. doi: 10.1371/journal.pone.0225913

82. Yang CH, Yue J, Pfeffer SR, Fan M, Paulus E, Hosni-Ahmed A, et al. MicroRNA-21 promotes glioblastoma tumorigenesis by down-regulating insulin-like growth factor-binding protein-3 (IGFBP3). J Biol Chem (2014) 289(36):25079-87. doi: 10.1074/jbc.M114.593863

83. Denduluri SK, Idowu O, Wang Z, Liao Z, Yan Z, Mohammed MK, et al. Insulin-like growth factor (IGF) signaling in tumorigenesis and the development of cancer drug resistance. Genes Dis (2015) 2(1):13-25. doi: 10.1016/j.gendis.2014.10.004

84. Zhu D, Tu M, Zeng B, Cai L, Zheng W, Su Z, et al. Up-regulation of miR-497 confers resistance to temozolomide in human glioma cells by targeting mTOR/Bcl-2. Cancer Med (2017) 6(2):452-62. doi: 10.1002/cam4.987

85. Tanksley JP, Chen X, Coffey RJ. NEDD4L is downregulated in colorectal cancer and inhibits canonical WNT signaling. PloS One (2013) 8(11):e81514. doi: 10.1371/journal.pone.0081514

86. He S, Deng J, Li G, Wang B, Cao Y, Tu Y. Down-regulation of Nedd4L is associated with the aggressive progression and worse prognosis of malignant glioma. Jpn J Clin Oncol (2012) 42(3):196-201. doi: 10.1093/ jjco/hyr195

87. Bao S, Wu Q, McLendon RE, Hao Y, Shi Q, Hjelmeland AB, et al. Glioma stem cells promote radioresistance by preferential activation of the DNA damage response. Nature (2006) 444(7120):756-60. doi: 10.1038/ nature 05236

88. Simpson AD, Soo YWJ, Rieunier G, Aleksic T, Ansorge O, Jones C, et al. Type 1 IGF receptor associates with adverse outcome and cellular radioresistance in paediatric high-grade glioma. Br J Cancer (2020) 122 (5):624-9. doi: 10.1038/s41416-019-0677-1

89. Brennan CW, Verhaak RG, McKenna A, Campos B, Noushmehr H, Salama SR, et al. The somatic genomic landscape of glioblastoma. Cell (2013) 155 (2):462-77. doi: 10.1016/j.cell.2013.09.034

90. Saleem H, Kulsoom Abdul U, Kucukosmanoglu A, Houweling M, Cornelissen FMG, Heiland DH, et al. The TICking clock of EGFR therapy resistance in glioblastoma: Target Independence or target Compensation. Drug Resist Update (2019) 43:29-37. doi: 10.1016/j.drup.2019.04.002

91. Chakravarti A, Loeffler JS, Dyson NJ. Insulin-like growth factor receptor I mediates resistance to anti-epidermal growth factor receptor therapy in primary human glioblastoma cells through continued activation of phosphoinositide 3-kinase signaling. Cancer Res (2002) 62(1):200-7.

92. Alamdari-Palangi V, Amini R, Karami H. MiRNA-7 enhances erlotinib sensitivity of glioblastoma cells by blocking the IRS-1 and IRS-2 expression. J Pharm Pharmacol (2020) 72(4):531-8. doi: 10.1111/jphp.13226

93. Drappatz J, Norden AD, Wen PY. Therapeutic strategies for inhibiting invasion in glioblastoma. Expert Rev Neurother (2009) 9(4):519-34. doi: 10.1586/ern.09.10

94. Verhaak RG, Hoadley KA, Purdom E, Wang V, Qi Y, Wilkerson MD, et al. Integrated genomic analysis identifies clinically relevant subtypes of glioblastoma characterized by abnormalities in PDGFRA, IDH1, EGFR, and NF1. Cancer Cell (2010) 17(1):98-110. doi: 10.1016/j.ccr.2009.12.020

95. Almiron Bonnin DA, Ran C, Havrda MC, Liu H, Hitoshi Y, Zhang Z, et al. Insulin-Mediated Signaling Facilitates Resistance to PDGFR Inhibition in Proneural hPDGFB-Driven Gliomas. Mol Cancer Ther (2017) 16(4):705-16. doi: 10.1158/1535-7163.MCT-16-0616

96. Pyonteck SM, Akkari L, Schuhmacher AJ, Bowman RL, Sevenich L, Quail DF, et al. CSF-1R inhibition alters macrophage polarization and blocks glioma progression. Nat Med (2013) 19(10):1264-72. doi: 10.1038/nm.3337

97. Ries $\mathrm{CH}$, Cannarile MA, Hoves S, Benz J, Wartha $\mathrm{K}$, Runza V, et al. Targeting tumor-associated macrophages with anti-CSF-1R antibody reveals a strategy for cancer therapy. Cancer Cell (2014) 25(6):846-59. doi: 10.1016/j.ccr.2014.05.016

98. Quail DF, Bowman RL, Akkari L, Quick ML, Schuhmacher AJ, Huse JT, et al. The tumor microenvironment underlies acquired resistance to CSF-1R inhibition in gliomas. Science (2016) 352(6288):aad3018. doi: 10.1126/science.aad3018

99. Rodvold JJ, Xian S, Nussbacher J, Tsui B, Cameron Waller T, Searles SC, et al. IRElalpha and IGF signaling predict resistance to an endoplasmic reticulum stress-inducing drug in glioblastoma cells. Sci Rep (2020) 10 (1):8348. doi: 10.1038/s41598-020-65320-6

100. Tirrò E, Martorana F, Romano C, Vitale SR, Motta G, Di Gregorio S, et al. Molecular Alterations in Thyroid Cancer: From Bench to Clinical Practice. Genes (Basel) (2019) 10(9):709-41. doi: 10.3390/genes10090709

101. Massimino M, Tirro E, Stella S, Frasca F, Vella V, Sciacca L, et al. Effect of Combined Epigenetic Treatments and Ectopic NIS Expression on Undifferentiated Thyroid Cancer Cells. Anticancer Res (2018) 38 (12):6653-62. doi: 10.21873/anticanres.13032

102. Tirrò E, Massimino M, Romano C, Pennisi MS, Stella S, Vitale SR, et al. Chk1 Inhibition Restores Inotuzumab Ozogamicin Citotoxicity in CD22-Positive Cells Expressing Mutant p53. Front Oncol (2019) 9:57:57. doi: 10.3389/fonc.2019.00057

103. Tirrò E, Massimino M, Stella S, Zammit V, Consoli ML, Pennisi MS, et al. Efficacy of Nilotinib in a CML Patient Expressing the Three-way Complex Variant Translocation t (). Anticancer Res (2019) 39(7):3893-9. doi: 10.21873/anticanres.13540

104. Andrews DW, Resnicoff M, Flanders AE, Kenyon L, Curtis M, Merli G, et al. Results of a pilot study involving the use of an antisense oligodeoxynucleotide directed against the insulin-like growth factor type I receptor in malignant astrocytomas. J Clin Oncol (2001) 19(8):2189-200. doi: 10.1200/JCO.2001.19.8.2189

105. Trojan J, Cloix JF, Ardourel MY, Chatel M, Anthony DD. Insulin-like growth factor type I biology and targeting in malignant gliomas. Neuroscience (2007) 145(3):795-811. doi: 10.1016/j.neuroscience. 2007.01.021

106. Ly A, Duc HT, Kalamarides M, Trojan LA, Pan Y, Shevelev A, et al. Human glioma cells transformed by IGF-I triple helix technology show immune and apoptotic characteristics determining cell selection for gene therapy of glioblastoma. Mol Pathol (2001) 54(4):230-9. doi: 10.1136/mp.54.4.230 
107. Andrews DW, Garcia S, Judy KD, Harshyne LA, Govindarajan S, Kenyon L, et al. Abstract CT038: Results of a Phase Ib trial of an autologous cell vaccine for newly diagnosed glioblastoma. Cancer Res (2019) 79:CT038-8. doi: 10.1158/1538-7445.SABCS18-CT038

108. Zhou X, Shen F, Ma P, Hui H, Pei S, Chen M, et al. GSK1838705A, an IGF$1 \mathrm{R}$ inhibitor, inhibits glioma cell proliferation and suppresses tumor growth in vivo. Mol Med Rep (2015) 12(4):5641-6. doi: 10.3892/mmr.2015.4129

109. Zhou X, Zhao X, Li X, Ping G, Pei S, Chen M, et al. PQ401, an IGF-1R inhibitor, induces apoptosis and inhibits growth, proliferation and migration of glioma cells. J Chemother (2016) 28(1):44-9. doi: 10.1179/ 1973947815Y.0000000026

110. Premkumar DR, Jane EP, Pollack IF. Co-administration of NVP-AEW541 and dasatinib induces mitochondrial-mediated apoptosis through Bax activation in malignant human glioma cell lines. Int J Oncol (2010) 37 (3):633-43. doi: 10.3892/ijo_00000712

111. Simpson A, Petnga W, Macaulay VM, Weyer-Czernilofsky U, Bogenrieder T. Insulin-Like Growth Factor (IGF) Pathway Targeting in Cancer: Role of the IGF Axis and Opportunities for Future Combination Studies. Targ Oncol (2017) 12(5):571-97. doi: 10.1007/s11523-017-0514-5

112. Zamykal M, Martens T, Matschke J, Gunther HS, Kathagen A, Schulte A, et al. Inhibition of intracerebral glioblastoma growth by targeting the insulin- like growth factor 1 receptor involves different context-dependent mechanisms. Neuro Oncol (2015) 17(8):1076-85. doi: 10.1093/neuonc/ nou344

113. Fouladi M, Perentesis JP, Wagner LM, Vinks AA, Reid JM, Ahern C, et al. A Phase I Study of Cixutumumab (IMC-A12) in Combination with Temsirolimus (CCI-779) in Children with Recurrent Solid Tumors: A Children's Oncology Group Phase I Consortium Report. Clin Cancer Res (2015) 21(7):1558-65. doi: 10.1158/1078-0432.CCR-14-0595

Conflict of Interest: The authors declare that the research was conducted in the absence of any commercial or financial relationships that could be construed as a potential conflict of interest.

Copyright (๑) 2021 Tirrò, Massimino, Romano, Martorana, Pennisi, Stella, Pavone, Di Gregorio, Puma, Tomarchio, Vitale, Manzella and Vigneri. This is an open-access article distributed under the terms of the Creative Commons Attribution License (CC BY). The use, distribution or reproduction in other forums is permitted, provided the original author(s) and the copyright owner(s) are credited and that the original publication in this journal is cited, in accordance with accepted academic practice. No use, distribution or reproduction is permitted which does not comply with these terms. 